\title{
Interspinous process decompression is associated with a reduction in opioid analgesia in patients with lumbar spinal stenosis
}

This article was published in the following Dove Press journal: Journal of Pain Research

\author{
Pierce D Nunley' \\ Timothy R Deer ${ }^{2}$ \\ Ramsin M Benyamin ${ }^{3}$ \\ Peter S Staats ${ }^{4}$ \\ Jon E Block ${ }^{5}$ \\ 'Spine Institute of Louisiana, \\ Shreveport, LA 7IIOI, USA; ${ }^{2}$ Center \\ for Pain Relief, Charleston, WV \\ 2530I, USA; ${ }^{3}$ Millennium Pain Center, \\ Bloomington, IL 6I704, USA; ${ }^{4}$ National \\ Spine and Pain Centers, Rockville, MD \\ 20852, USA; JJon Block, San Francisco, \\ CA 94115 , USA
}

Correspondence: Jon E Block Jon Block,

2210 Jackson Street, Suite 40I, San Francisco, CA 94II5, USA

Tel +I 4I5 7757947

Email jb@drjonblock.com
Background: Lumbar spinal stenosis (LSS) causes significant pain and functional impairment, and medical management has increasingly included the prescription of opioid-based analgesics. Interspinous process decompression (IPD) provides a minimally-invasive treatment option for LSS. Methods: This study estimated the type, dosage, and duration of opioid medications through 5 years of follow-up after IPD with the Superion Indirect Decompression System (Vertiflex Inc., Carlsbad, CA USA). Data were obtained from the Superion-treatment arm of a randomized controlled noninferiority trial. The prevalence of subjects using opiates was determined at baseline through 60 months. Primary analysis included all 190 patients randomized to receive the Superion device. In a subgroup of 98 subjects, we determined opioid-medication prevalence among subjects with a history of opioid use.

Results: At baseline, almost 50\% (94 of 190) of subjects were using opioid medication. Thereafter, there was a sharp decrease in opioid-medication prevalence from $25.2 \%$ (41 of 163) at 12 months to $13.3 \%$ (20 of 150) at 24 months to $7.5 \%$ ( 8 of 107) at 60 months. Between baseline and 5 years, there was an $85 \%$ decrease in the proportion of subjects using opioids. A similar pattern was also observed among subjects with a history of opiates prior to entering the trial.

Conclusion: Stand-alone IPD is associated with a marked decrease in the need for opioid medications to manage symptoms related to LSS. In light of the current opiate epidemic, such alternatives as IPD may provide effective pain relief in patients with LSS without the need for opioid therapy.

Keywords: interspinous spacer, Superion, lumbar spinal stenosis, opioids, neurogenic claudication, indirect decompression

\section{Introduction}

Lumbar spinal stenosis (LSS) is a common degenerative condition that causes significant pain, disability, functional impairment, and diminished quality of life. ${ }^{1-5}$ The clinical feature most commonly attributed to LSS is neurogenic claudication that involves leg symptoms encompassing the buttocks, groin, and anterior thigh, as well as radiating pain down the posterior aspect of the leg to the feet. ${ }^{3,6}$ The discomfort associated with LSS is often described as a cramping or burning feeling. Symptoms of neurogenic claudication can be distributed unilaterally or bilaterally, and the patient may suffer concomitant back pain, although leg pain and discomfort are usually more bothersome. $^{7}$

A distinguishing clinical attribute of neurogenic claudication is its relationship to the patient's posture, where lumbar extension increases and flexion decreases pain onset and severity. Symptoms progressively worsen when standing or walking, and are relieved 
by sitting and bending forward. In addition to the cardinal clinical feature of neurogenic claudication, patients often complain of symptoms that are more radicular in nature, with sharp lower-extremity pain. Leg pain is described as severe and radicular in distribution, and almost always presents with postural aggravation during lumbar extension. ${ }^{6,8}$ LSS is the most common indication for spine surgery in older adults.

Conservative medical management of chronic spinal pain disorders, including LSS, has increasingly included the

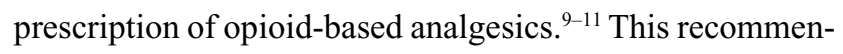
dation has been based on the belief that these medications can relieve pain and improve function and quality of life in selected patients. ${ }^{12}$ In fact, opiates have become the most commonly prescribed class of drug for back pain, based on insurance-claim data. ${ }^{13}$ Additionally, it has been estimated that more than half of regular opioid users report back pain as a primary complaint. ${ }^{14}$

Unfortunately, despite initial enthusiasm for opioid therapy, it has only recently been demonstrated that opioid analgesics offer little clinical benefit by way of pain reduction or functional improvement in patients with chronic musculoskeletal pain, including LSS. ${ }^{15-20}$ Moreover, the odds of an opioid-related adverse event are three times that compared to placebo among older adults with musculoskeletal pain. ${ }^{20}$ Specifically, Markman et $\mathrm{l}^{19}$ failed to demonstrate any clinical benefit of opiates in older patients experiencing neurogenic claudication secondary to LSS.

Based on emerging evidence raising concerns over the ineffectiveness and possible hazards of opioid medications in the treatment of chronic low-back and leg pain, the British National Institute for Health and Care Excellence updated their recommendation for the assessment and management of low-back pain and sciatica. ${ }^{21}$ They concluded, "Do not offer opioids for managing low back pain". Consequently, there is an urgent need to reverse the trend in opioid prescribing being a primary strategy for patients with LSS.

There is a growing body of published literature to support the safety and effectiveness of interspinous process decompression (IPD) with stand-alone interspinous spacers in the treatment of moderate LSS. ${ }^{22,23}$ Spacers provide immediate symptom amelioration by serving as a spinal extension blocker to prevent the repetitive compression of neurovascular elements during back extension that is the primary source of LSS symptoms. Clinical follow-up from a US Food and Drug Administration (FDA) investigational device exemption (IDE) randomized controlled trial of the Superion device extends to 5 years of published findings. ${ }^{24}$ Durable and clinically significant improvements have been demonstrated following spacer implantation in conditionspecific impairment, leg- and back-pain severity, functional disability, and health-related quality of life. The degree of clinical improvement achieved with spacers appears to be strikingly similar to the improvement achieved with decompressive laminectomy, long considered the "gold standard" for surgical treatment of LSS. ${ }^{25}$

Owing to the magnitude, stability, and longevity of clinical benefit observed among LSS patients treated with IPD, we have undertaken additional analyses of ancillary variables in our IDE trial that may have a direct impact on health care utilization. This report examines and characterizes the opioid-medication-usage patterns among patients treated with stand-alone IPD through 5 years of postoperative follow-up.

\section{Methods}

Type, dosage, and duration of opioid medications through 5 years of postoperative follow-up were obtained from the Superion Indirect Decompression system (Vertiflex Inc., Carlsbad, CA, USA) treatment arm of a randomized controlled FDA IDE noninferiority trial comparing two interspinous spacers. Medication-prescribing history was documented and validated via electronic data-capture methods for all treated patients during their enrollment and participation as study subjects.

This multicenter trial evaluated the use of stand-alone IPD in the treatment of subjects aged 45 years or older with moderate symptoms of intermittent neurogenic claudication, secondary to a diagnosis of moderate degenerative LSS at one or two contiguous levels from L1 to L5. A total of 391 subjects met the trial-eligibility criteria and were randomized to treatment. The Superion was approved by the FDA in 2015 for commercial distribution based on the 2-year primary end-point analysis. ${ }^{23}$ Additionally, condition-specific clinical outcomes have been reported through 5 years of follow-up. ${ }^{24,26,27}$ Inasmuch as the control device (X-Stop IPD; Medtronic, Minneapolis, MN, USA) is no longer commercially available, the current opioid-medication analysis was restricted exclusively to the Superion arm of the trial.

This IDE trial complied with all US regulatory requirements and was approved by the institutional review board at each participating site, and patients provided written informed consent before any study-related procedures were performed. The trial was conducted in accordance with the Declaration of Helsinki and prospectively registered at ClinicalTrials.gov (NCT00692276).

Based on opioid-medication start date and duration of use, the prevalence of subjects using opiates was clas- 
sified by postoperative follow-up in the same intervals as other previously reported clinical outcomes from this trial (ie, baseline, 6 weeks, and 3, 6, 12, 18, 24, 36, 48, and 60 months). Previous (ie, prestudy) opioid-medication use prior to a subject's enrollment in the trial was also captured based on entrance-eligibility interviews that queried medication history for LSS.

Our primary analysis included all 190 patients randomized to receive the Superion device to determine opioid-medication prevalence. At each follow-up, medication-usage data were provided only for subjects free of reoperation or revision at the index surgical level. Sample sizes were 190 (baseline), 181 (6 weeks), 173 (3 months), 174 (6 months), 163 (12 months), 150 (18 months), 150 (24 months), 125 (36 months), 106 (48 months), and 107 (60 months). A second subgroup analysis was also undertaken after excluding all subjects that had initiated opiates after surgery $(n=92)$. In the remaining subgroup of 98 subjects, we determined opioid-medication prevalence in the same manner among subjects with a history of opioid use for LSS. Sample sizes in this subgroup were 98 (baseline), 90 (6 weeks), 87 (3 months), 87 (6 months), 84 (12 months), 74 (18 months), 79 (24 months), 66 (36 months), 54 (48 months), and 55 (60 months).

\section{Results}

Table 1 provides opioid-medication types and frequency of use among all study subjects through 60 months of clinical follow-up.

Among all study subjects, there was a marked yearon-year decrease in the proportion of patients prescribed opioid medications to manage LSS symptoms after Superion implantation (Figure 1). At baseline, almost 50\% (94 of

Table I Type and frequency of opioid medication usage

\begin{tabular}{|l|l|}
\hline Medication name & $\mathbf{n}(\%)$ \\
\hline Buprenorphine & $4(\mathrm{I} .27)$ \\
\hline Codeine & $\mathrm{I}(3.17)$ \\
\hline Dextropropoxyphene & $\mathrm{I}(0.32)$ \\
\hline Fentanyl & $2(0.63)$ \\
\hline Hydrocodone & $94(29.84)$ \\
\hline Hydromorphone & $37(\mathrm{II} .75)$ \\
\hline Methadone & $5(\mathrm{I} .59)$ \\
\hline Morphine & $7(2.22)$ \\
\hline Oxycodone & $95(30.16)$ \\
\hline Oxymorphone & $3(0.95)$ \\
\hline Tapentadol & $\mathrm{I}(0.32)$ \\
\hline Tramadol & $56(17.78)$ \\
\hline
\end{tabular}

Note: Data obtained from 190 Superion subjects prescribed multiple medication types $(n=315)$.
190) of subjects were using opioid medication, with a spike in opioid use $(64.1 \%, 116$ of 181) at the 6-week follow-up interval. After this early postoperative interval, there was a sharp diminution in opioid-medication prevalence from $25.2 \%$ (41 of 163 ) at 12 months to $13.3 \%$ (20 of 150 ) at 24 months to $7.5 \%$ (8 of 107) at 60 months. Overall, between baseline and 5 years, there was an $85 \%$ decrease in the proportion of subjects using opioids.

A similar pattern of decreased opioid-medication usage was also observed among the subgroup of subjects with a history of opiates at trial entry (Figure 2). At enrollment, $67.3 \%$ (66 of 98) reported prior opioid usage to manage LSS symptoms. By week 6, usage had dropped to $48.9 \%$ (44 of 90). Opioid-medication prevalence was 27.4\% (23 of 84 ) at 12 months, $15.2 \%$ (12 of 79) at 24 months, and 9.1\% ( 5 of 55) at 60 months. In this subgroup, between baseline and 5 years, there was an $82 \%$ decrease in the proportion of subjects using opioids.

\section{Discussion}

It has recently been reported in patients aged $\geq 65$ years with a new-back-pain visit that those filling two or more opioid prescriptions within 90 days of the visit had similar backrelated outcomes, but an increased likelihood of filling opioid prescriptions 18-24 months later, compared with matched patients who did not fill early opioid prescriptions. ${ }^{28}$ This finding suggests a dangerous opioid recidivism and underscores the need to reverse the trend in opioid-prescribing patterns among older patients with musculoskeletal pain syndromes, including LSS.

The large multicenter Spine Patient Outcome Research Trial (SPORT) trial of LSS reported opioid-usage prevalence of $27 \%$ at baseline prior to laminectomy. ${ }^{29}$ In our IDE trial, we found that $\sim 35 \%$ of patients randomized to receive Superion had a history of opioid use at enrollment in the study (Figure 1). We also noted that study subjects were perfunctorily prescribed opiates in the immediate postoperative period, raising the prevalence to $64 \%$ within 6 weeks of surgery.

However, after the early postsurgical period, we identified a marked diminution in the prevalence of opioid usage, dropping to $25 \%$ at 12 months and $13 \%$ by 24 months. These results compare favorably with opioid-prevalence estimates associated with other interventions for LSS. For example, in a randomized trial of repeated epidural steroid injections for LSS, Friedly et $\mathrm{al}^{30}$ reported baseline opioid-usage prevalence of $38 \%$ and 12 -month prevalence of $41 \%$, confirming and extending previous research demonstrating lack of long- 


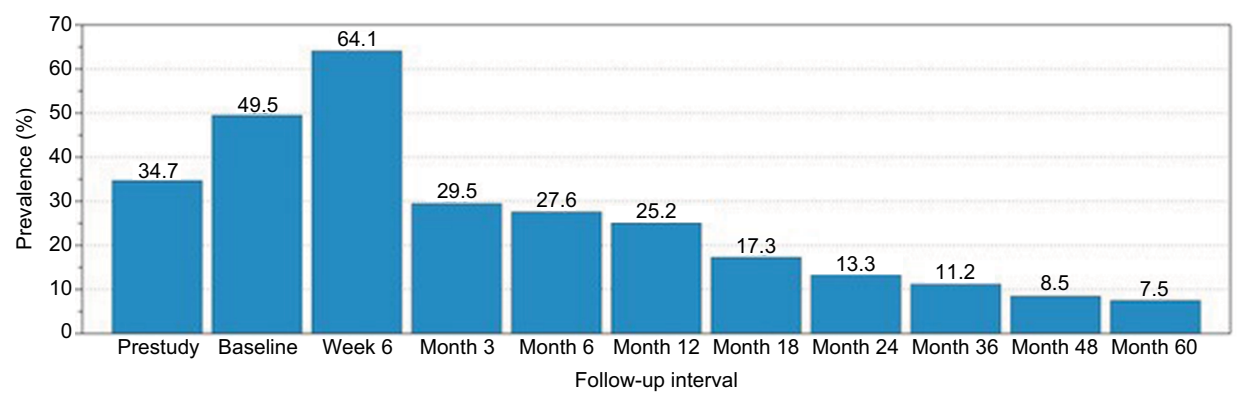

Figure I Opioid-medication prevalence (\%) by follow-up interval for all study subjects $(n=190)$.

Note: Sample sizes were 190 (prestudy, baseline), I8I (week 6), 173 (month 3), 174 (month 6), 163 (month 12), 150 (month 18), I50 (month 24 ), 125 (month 36 ), 106 (month 48), and 107 (month 60).

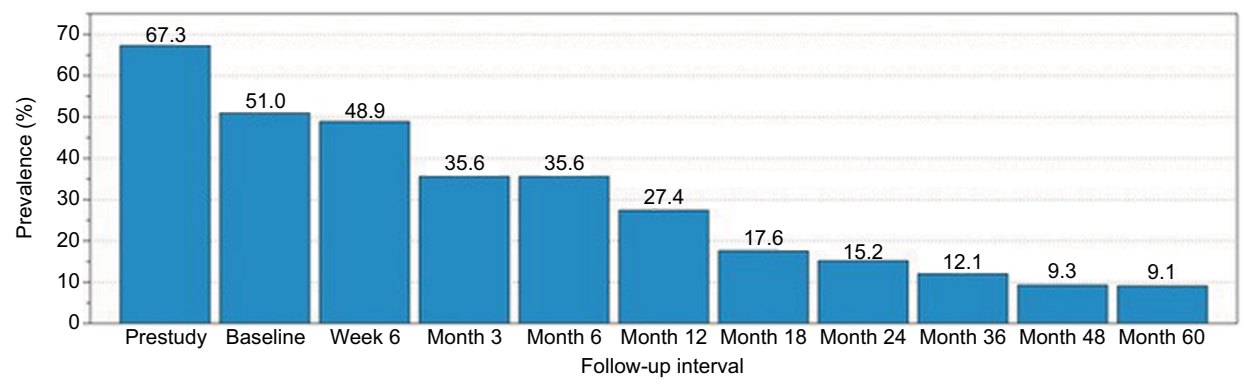

Figure 2 Opioid-medication prevalence $(\%)$ by follow-up interval for study subjects with opioid history $(\mathrm{n}=98)$.

Note: Sample sizes in this subgroup were 98 (prestudy, baseline), 90 (week 6), 87 (month 3), 87 (month 6), 84 (month 12), 74 (month 18), 79 (month 24 ), 66 (month 36 ), 54 (month 48), and 55 (month 60).

term effectiveness for epidural steroid injections for treating chronic LSS symptoms. ${ }^{31,32}$

Our results are also somewhat better than those realized after decompressive laminectomy. In a randomized controlled IDE trial, Schmidt et al $^{33}$ reported prestudy opioid-usage prevalence of $31 \%$, spiking postsurgically to $67 \%$, then decreasing to $19 \%$ at 12 months, and $23 \%$ by 24 months following laminectomy. In our trial, the prevalence of opioid usage continued to drop precipitously to $7.5 \%$ by 60 months. It is unknown whether postlaminectomy patients enjoy a similarly rapid decrease in opioid usage with longer-term follow-up. However, if laminectomy-associated instability ensues and symptoms reemerge, revision to fusion may be necessary, requiring reestablishment of opiate therapy.

Many patients expect spine surgery to eliminate the need for opioids. Indeed, prior to lumbar fusion surgery, over $90 \%$ of patients surveyed considered continued dependence on opioids neither an expected nor acceptable outcome. ${ }^{34}$ In a retrospective cohort study of 2,492 patients having lumbar fusion surgery for degenerative conditions, including LSS, Deyo et $\mathrm{a}^{35}$ found that more patients received long-term opioids postoperatively $(n=1,094)$ than preoperatively $(n=1,045)$. Additionally, opioid-naïve patients had a substantial risk of initiating long-term use.
Increasing utilization of opioid medications as part of a treatment regime to manage chronic pain has been associated with drug misuse, complications, and fatal overdoses. ${ }^{36}$ This problem is even more acute in older adults, who are more susceptible to the adverse effects of opioids, such as disorientation, syncope, and falls. ${ }^{37}$ We found that stand-alone IPD in older patients with LSS substantially reduced the need for opioid medication through 5 years of postoperative followup. This finding mirrors a similarly notable reduction in need for reoperation or revision following IPD. We previously reported that $75 \%$ (142 of 190) of IPD subjects were free of reoperation at their index level through 5 years of follow-up. ${ }^{24}$ Importantly, among the 48 spacer subjects that had a reoperation, 38 (79\%) subjects underwent their reoperation within the initial 24 months of follow-up. Only a single reoperation occurred during the fifth year of observation, suggesting a continuously decreasing risk of revision surgery with time. The compilation of results from this IDE trial demonstrates long-term durable improvements in condition-specific pain and functional outcomes, as well as marked reductions in the need for opioid medication and revision surgery with IPD through 5 years of follow-up.

This study has several limitations. In the absence of a nonsurgical control, we were unable to estimate the 
comparative natural history of opioid usage among LSS patients treated conservatively. Although medication prescribing was captured on a compulsory basis for all study subjects, the trial was not designed to evaluate opioid usage as a primary or secondary outcome. As an ancillary variable, data collection methods lacked a standardized methodology to quantify opioid usage. Consequently, our post hoc analysis was constrained to prevalence estimates within specified postoperative follow-up intervals and limited only to those patients who remained implanted with the study device and who were free of a reoperation at the index surgical level.

\section{Conclusion}

Stand-alone IPD is associated with a marked and sustained decrease in the need for opioid medications to manage symptoms related to LSS. This finding extends previous results showing long-term sustained clinical improvements, a reduction in symptoms of neurogenic claudication, and a decreasing requirement for revision surgery in this population.

\section{Data sharing statement}

Requests for data sharing can be made by contacting the corresponding author. Individual participant data that underlie the results reported in this article will be made available (after deidentification) from 9 to 36 months after article publication. Data sharing will be limited to investigators whose proposed use of the data has been approved by an independent review committee identified for this purpose.

\section{Acknowledgments}

The authors wish to thank Bob Hachadoorian for datamanagement support and conducting all statistical analyses. Graphic support was provided by Terry Meredith. Financial support for this work was provided by Vertiflex Inc. (Carlsbad, CA, USA).

\section{Author contributions}

All authors contributed to data analysis, drafting and revising the article, gave final approval of the version to be published, and agree to be accountable for all aspects of the work.

\section{Disclosure}

JEB is an independent advisor to Vertiflex Inc. and was remunerated for assistance in manuscript development. The other authors report no conflicts of interest in this work.

\section{References}

1. Arbit E, Pannullo S. Lumbar stenosis: a clinical review. Clin Orthop Relat Res. 2001;384(384):137-143.

2. Benoist M. The natural history of lumbar degenerative spinal stenosis. Joint Bone Spine. 2002;69(5):450-457.

3. Binder DK, Schmidt MH, Weinstein PR. Lumbar spinal stenosis. Semin Neurol. 2002;22(2):157-166.

4. Chad DA. Lumbar spinal stenosis. Neurol Clin. 2007;25(2): 407-418.

5. Conway J, Tomkins CC, Haig AJ. Walking assessment in people with lumbar spinal stenosis: capacity, performance, and self-report measures. Spine J. 2011;11(9):816-823.

6. Genevay S, Atlas SJ, Lumbar spinal stenosis. Best Pract Res Clin Rheumatol. 2010;24(2):253-265.

7. Lee SY, Kim TH, Oh JK, Lee SJ, Park MS. Lumbar stenosis: a recent update by review of literature. Asian Spine J. 2015;9(5):818-828.

8. Lurie J, Tomkins-Lane C. Management of lumbar spinal stenosis. BMJ. 2016;352:h6234.

9. American Geriatrics Society Panel on Pharmacological Management of Persistent Pain in Older Persons. Pharmacological management of persistent pain in older persons. J Am Geriatr Soc. 2009;57(8):1331-1346.

10. Chou R, Fanciullo GJ, Fine PG, et al. Clinical guidelines for the use of chronic opioid therapy in chronic noncancer pain. $J$ Pain. 2009;10(2):113-130.

11. Dowell D, Haegerich TM, Chou R. CDC guideline for prescribing opioids for chronic pain-United States, 2016. JAMA. 2016;315(15): 1624-1645.

12. Ballantyne JC, Mao J. Opioid therapy for chronic pain. N Engl J Med. 2003;349(20):1943-1953.

13. Ivanova JI, Birnbaum HG, Schiller M, Kantor E, Johnstone BM, Swindle RW. Real-world practice patterns, health-care utilization, and costs in patients with low back pain: the long road to guideline-concordant care. Spine J. 2011;11(7):622-632.

14. Hudson TJ, Edlund MJ, Steffick DE, Tripathi SP, Sullivan MD. Epidemiology of regular prescribed opioid use: results from a national, population-based survey. J Pain Symptom Manage. 2008;36(3):280-288.

15. Abdel Shaheed C, Maher CG, Williams KA, Day R, McLachlan AJ. Efficacy, Tolerability, and dose-dependent effects of opioid analgesics for low back pain: a systematic review and meta-analysis. JAMA Intern Med. 2016;176(7):958-968.

16. Chaparro LE, Furlan AD, Deshpande A, Mailis-Gagnon A, Atlas S, Turk DC. Opioids compared with placebo or other treatments for chronic low back pain: an update of the Cochrane review. Spine. 2014;39(7):556-563.

17. Chou R, Deyo R, Friedly J, et al. Systemic pharmacologic therapies for low back pain: a systematic review for an American College of Physicians Clinical Practice Guideline. Ann Intern Med. 2017;166(7):480-492.

18. Krebs EE, Gravely A, Nugent S, et al. Effect of opioid vs nonopioid medications on pain-related function in patients with chronic back pain or hip or knee osteoarthritis pain: the SPACE randomized clinical trial. JAMA. 2018;319(9):872-882.

19. Markman JD, Gewandter JS, Frazer ME, et al. A randomized, doubleblind, placebo-controlled crossover trial of oxymorphone hydrochloride and propoxyphene/acetaminophen combination for the treatment of neurogenic claudication associated with lumbar spinal stenosis. Spine. 2015;40(10):684-691.

20. Megale RZ, Deveza LA, Blyth FM, et al. efficacy and safety of oral and transdermal opioid analgesics for musculoskeletal pain in older adults: a systematic review of randomized, placebo-controlled trials. $J$ Pain. 2018;19(5):475.e471-e475.

21. Bernstein IA, Malik Q, Carville S, Ward S. Low back pain and sciatica: summary of NICE guidance. BMJ. 2017;356:16748.

22. Nunley PD, Shamie AN, Blumenthal SL, Orndorff D, Block JE, Geisler FH. Interspinous process decompression: expanding treatment options for lumbar spinal stenosis. Biomed Res Int. 2016;2016:3267307. 
23. Patel VV, Whang PG, Haley TR, et al. Superion interspinous process spacer for intermittent neurogenic claudication secondary to moderate lumbar spinal stenosis: two-year results from a randomized controlled FDA-IDE pivotal trial. Spine. 2015;40(5):275-282.

24. Nunley PD, Patel VV, Orndorff DG, Lavelle WF, Block JE, Geisler FH. Five-year durability of stand-alone interspinous process decompression for lumbar spinal stenosis. Clin Interv Aging. 2017;12:1409-1417.

25. Lauryssen C, Jackson RJ, Baron JM, et al. Stand-alone interspinous spacer versus decompressive laminectomy for treatment of lumbar spinal stenosis. Expert Rev Med Devices. 2015;12(6):763-769.

26. Nunley PD, Patel VV, Orndorff DG, Lavelle WF, Block JE, Geisler FH. Superion interspinous spacer treatment of moderate spinal stenosis: 4-year results. World Neurosurg. 2017;104:279-283.

27. Patel VV, Nunley PD, Whang PG, et al. Superion ${ }^{\circledR}$ InterSpinous Spacer for treatment of moderate degenerative lumbar spinal stenosis: durable three-year results of a randomized controlled trial. J Pain Res. 2015;8:657-662.

28. Gold LS, Hansen RN, Avins AL, et al. Associations of early opioid use with patient-reported outcomes and health care utilization among older adults with low back pain. Clin J Pain. 2018;34(4):297-305.

29. Weinstein JN, Tosteson TD, Lurie JD, et al. Surgical versus nonoperative treatment for lumbar spinal stenosis four-year results of the Spine Patient Outcomes Research Trial. Spine. 2010;35(14):1329-1338.
30. Friedly JL, Comstock BA, Turner JA, et al. Long-term effects of repeated injections of local anesthetic with or without corticosteroid for lumbar spinal stenosis: a randomized trial. Arch Phys Med Rehabil. 2017;98(8):1499-1507.

31. Andersson GB. Epidural glucocorticoid injections in patients with lumbar spinal stenosis. N Engl J Med. 2014;371(1):75-76.

32. Friedly JL, Comstock BA, Turner JA, et al. A randomized trial of epidural glucocorticoid injections for spinal stenosis. $N$ Engl J Med. 2014;371(1):11-21.

33. Schmidt S, Franke J, Rauschmann M, Adelt D, Bonsanto MM, Sola S. Prospective, randomized, multicenter study with 2-year follow-up to compare the performance of decompression with and without interlaminar stabilization. J Neurosurg Spine. 2018;28(4):406-415.

34. Carragee EJ, Cheng I. Minimum acceptable outcomes after lumbar spinal fusion. Spine J. 2010;10(4):313-320.

35. Deyo RA, Hallvik SE, Hildebran C, et al. Use of prescription opioids before and after an operation for chronic pain (lumbar fusion surgery). Pain. 2018;159(6):1147-1154.

36. Okie S. A flood of opioids, a rising tide of deaths. $N$ Engl J Med. 2010;363(21):1981-1985.

37. Deyo RA, von Korff M, Duhrkoop D. Opioids for low back pain. $B M J$. 2015;350:g6380.
Journal of Pain Research

\section{Publish your work in this journal}

The Journal of Pain Research is an international, peer reviewed, open access, online journal that welcomes laboratory and clinical findings in the fields of pain research and the prevention and management of pain. Original research, reviews, symposium reports, hypothesis formation and commentaries are all considered for publication.

\section{Dovepress}

The manuscript management system is completely online and includes a very quick and fair peer-review system, which is all easy to use. Visit http://www.dovepress.com/testimonials.php to read real quotes from published authors. 